\title{
Comparative analysis of the liver transcriptome in the red- eared slider turtle Trachemys scripta elegans under chronic salinity stress
}

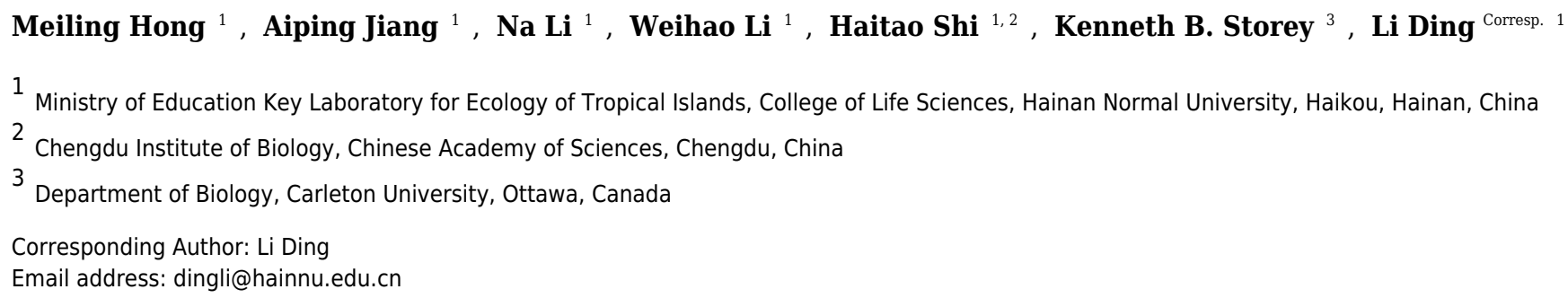

The red-eared slider (Trachemys scripta elegans), identified as one of the 100 most invasive species in the world, is a freshwater turtle originally from the eastern United States and northeastern Mexico. Field investigations have shown that $T$. s. elegans can survive and lay eggs in saline habitats. In order to understand the molecular mechanisms of salinity adaptation, high-throughput RNA-Seq was utilized to identify the changes in gene expression profiles in the liver of $T$. s. elegans in response to elevated salinity. We exposed individuals to 0,5 , or 15 psu (practical salinity units) for 30 days. A total of 157.21 million reads were obtained and assembled into 205138 unigenes with an average length of $620 \mathrm{bp}$ and N50 of $964 \mathrm{bp}$. Of these, 1019 DEGs (differentially expressed genes) were found in the comparison of 0 vs 5 psu, 1194 DEGs in 0 vs 15 psu and 1180 DEGs in 5 vs 15 psu, which are mainly related to macromolecule metabolic process, ion transport, oxidoreductase activity and generation of precursor metabolites and energy by GO (Gene Ontology) enrichment analyses. T. s. elegans can adapt itself into salinity adaptation by balancing the entry of sodium and chloride ions via the up-regulation expression genes of ion transport (potassium voltage-gated channel subfamily $\mathrm{H}$ member $5, \mathrm{KCNH} 5$; erine/threonine-protein kinase 32, STK32; salt-inducible kinase 1, SIK1; adiponectin, $A(D C)$, and by accumulating plasma urea and free amino acid via the up-regulation expression genes of amino acid metabolism (ornithine decarboxylase antizyme 3, OAZ3; glutamine synthetase, GLUL; asparaginase-like protein 1b, ASRGL; L-amino-acid oxidaselike, LAAO; sodium-dependent neutral amino acid transporter $B, S L C 6 A 15 s$; amino acid permease, SLC7A9) in response to osmotic regulation. An investment of energy to maintain their homeostatic balance is required to salinity adaptation, therefore, the genes related to energy production and conversion (F-ATPase protein 6, ATP6; cytochrome $c$ oxidase subunit I, COX1; cytochrome c oxidase subunit III, COX3; cytochrome b, CYTb; 
cytochrome P450 17A1, CYP17A1) were up-regulated with the increase of gene expression associated with lipid metabolism (apolipoprotein E precursor, $A P O E$; coenzyme Q-binding protein, CoQ10; high-density lipoprotein particle, SAA) and carbohydrate metabolism (HK, $M I P)$. These findings improve our understanding of the underlying molecular mechanisms involved in salinity adaptation and provide general guidance to illuminate the invasion potential of $T$. s. elegans into saline environments. 
1 Comparative analysis of the liver transcriptome in the red-eared

2 slider turtle Trachemys scripta elegans under chronic salinity stress

3 Meiling Hong ${ }^{1}$, Aiping Jiang1, Na Li ${ }^{1}$, Weihao Li ${ }^{1}$, Haitao Shi ${ }^{1,2}$, Kenneth B. Storey ${ }^{3}$, Li

4 Ding ${ }^{1^{*}}$

5

61 Ministry of Education Key Laboratory for Ecology of Tropical Islands, College of Life

7 Sciences, Hainan Normal University, Haikou, China

82 Chengdu Institute of Biology, Chinese Academy of Sciences, Chengdu, China

93 Department of Biology, Carleton University, Ottawa, Canada K1S 5B6

10

11 * Corresponding author: Dr. Li Ding

12 Telephone: $+86-898-65883521$

13 E-mail: dingli@hainnu.edu.cn 
14

15

16

17

\section{ABSTRACT}

The red-eared slider (Trachemys scripta elegans), identified as one of the 100 most invasive species in the world, is a freshwater turtle originally from the eastern United States and northeastern Mexico. Field investigations have shown that $T$. s. elegans can survive and lay eggs in saline habitats. In order to understand the molecular mechanisms of salinity adaptation, highthroughput RNA-Seq was utilized to identify the changes in gene expression profiles in the liver of T. s. elegans in response to elevated salinity. We exposed individuals to 0,5 , or $15 \mathrm{psu}$ (practical salinity units) for 30 days. A total of 157.21 million reads were obtained and assembled into 205138 unigenes with an average length of $620 \mathrm{bp}$ and N50 of $964 \mathrm{bp}$. Of these, 1019 DEGs (differentially expressed genes) were found in the comparison of 0 vs 5 psu, 1194 DEGs in 0 vs 15 psu and 1180 DEGs in 5 vs 15 psu, which are mainly related to macromolecule metabolic process, ion transport, oxidoreductase activity and generation of precursor metabolites and energy by GO (Gene Ontology) enrichment analyses. T. s. elegans can adapt itself into salinity adaptation by balancing the entry of sodium and chloride ions via the up-regulation expression genes of ion transport (potassium voltage-gated channel subfamily $\mathrm{H}$ member 5 , KCNH5; erine/threonine-protein kinase 32, STK32; salt-inducible kinase 1, SIK1; adiponectin, $A C D C$ ), and by accumulating plasma urea and free amino acid via the up-regulation expression genes of amino acid metabolism (ornithine decarboxylase antizyme 3, OAZ3; glutamine synthetase, GLUL; asparaginase-like protein 1b, $A S R G L$; L-amino-acid oxidase-like, $L A A O$; sodium-dependent neutral amino acid transporter B, SLC6A15s; amino acid permease, SLC7A9) in response to osmotic regulation. An investment of energy to maintain their homeostatic balance 
35 is required to salinity adaptation, therefore, the genes related to energy production and

36 conversion (F-ATPase protein 6, ATP6; cytochrome c oxidase subunit I, COX1; cytochrome c

37 oxidase subunit III, $C O X 3$; cytochrome b, $C Y T b$; cytochrome P450 17A1, CYP17A1) were up-

38 regulated with the increase of gene expression associated with lipid metabolism (apolipoprotein

39 E precursor, $A P o E$; coenzyme Q-binding protein, $C o Q 10$; high-density lipoprotein particle, $S A A$ )

40 and carbohydrate metabolism $(H K, M I P)$. These findings improve our understanding of the

41 underlying molecular mechanisms involved in salinity adaptation and provide general guidance

42 to illuminate the invasion potential of T. s. elegans into saline environments. 


\section{INTRODUCTION}

The red-eared slider turtle (Trachemys scripta elegans) has been introduced into diverse aquatic habitats worldwide (including many countries in Africa, Asia and Europe as well as Australia) via the pet-release pathway and, as a result, is classified as a highly invasive species

by the International Union for Conservation of Nature (Luiselli et al., 1997; Martins et al., 2014).

It is native to freshwater habitats in 19 states of the eastern United States and two states of northeastern Mexico (Mittermeier et al., 2015). Recently these turtles have been found to lay eggs in the low salinity (0.1-26\%o) estuary of the Nandujiang in Hainan Province, China (Liu et al., 2011; Yang \& Shi 2014). The extent of the saltwater adaptability of T. s. elegans is not fully understood. Studies of endocrine stress responses by T. s. elegans in the Lake Pontchartrain Basin of Louisiana suggest that these turtles may serve as a sentinel species for elevated salinity in environments where salinity is rising due to saltwater intrusion (Thompson et al., 2011). These studies indicate that T. s. elegans can invade not only fresh water, but also saline water environments. Therefore, the invasion potential and the mechanism of response to salinity adaptation of T. s. elegans is of serious concern.

Changing levels of salinity are a crucial environmental stress factor for aquatic species that can disrupt electrolyte balance, cell energetics, and various other physiological responses, including activating stress hormones (Lushchak 2011). Species show altered composition the osmolality of body fluids in response to changing salinity (Charmantier et al., 2011) and adaptation to salinity change typically involves the physiological solution: tolerance of elevated inorganic ion concentrations (mainly sodium and chloride) in plasma (Gordon \& Tucker 1965), 
64 and accumulation of organic osmolytes (e.g. urea) to counteract cell-volume changes. The most dramatic changes in urea concentration are seen in plasma and tissues such as skeletal muscle, resulting from the up-regulation of hepatic urea (Wright et al., 2004). Accumulation of intracellular free amino acids via hepatic protein degradation or de novo amino acid synthesis can also contribute to osmotic balance (McNamara et al., 2004; Yancey 1985). When subjected to ambient salinity change, $T$. s. elegans increased serum glucose levels, and the activities of creatine kinase (CK), aspartate aminotransferase (AST), lactate dehydrogenase (LDH), and alkaline phosphatase (ALP) in liver (Shu et al., 2012). Our previous studies have shown that T. s. elegans can increase blood osmotic pressure by balancing the entry of sodium and chloride ions with a decrease in the secretion of aldosterone, and by accumulating plasma urea for osmoregulation when ambient salinity was lower than 15\% (Hong et al., 2014). However the molecular basis of these adaptive responses has not been studied in T. s. elegans.

Recently, high-throughput next-generation sequencing techniques have allowed researchers to broadly explore the extent and complexity of the transcriptomes of a wide range of eukaryotic species including to gain novel information about the gene responses of aquatic species to physiological and environmental stresses (Wang et al., 2009). RNA-seq is an efficient technique to probe the gene responses to physiological stress (Li et al., 2013; Smith et al., 2013; Xia et al., 2013), particularly when working with species that do not have a sequenced genome. The present study used RNA-seq to analyze the transcriptomic response of T. s. elegans to salinity stress and identify the genes (and their metabolic functions) that are involved in salinity adaptation of turtles challenged by a brackish water environment. These results provide insights into the 
85

86

87

88

89

90

91

92

93

94

95

96

97

98

99

100

101

102

103

104

molecular mechanisms underlying osmoregulation in T. s. elegans and address the potential for this species to further invade and spread through new aquatic and brackish territories.

\section{MATERIALS AND METHODS}

\section{Animals}

Healthy T. s. elegans were obtained from a local turtle farm in Hainan Province, China and were acclimated in three cement pools half-filled with freshwater for two weeks. After acclimatization, nine healthy $T$. s. elegans (BW: 424-478g, 2 years old) were divided into three groups in pools $(190 \mathrm{~cm} \times 65 \mathrm{~cm} \times 32 \mathrm{~cm})$ of differing salinity: one in freshwater serving as the control ( 0 practical salinity units, psu), and the other two challenged with $5 \%$ (5 psu) or $15 \%$ (15 psu) saltwater. Turtles were fed a commercial diet each Monday and Thursday and $24 \mathrm{~h}$ after feeding, unused feed was siphoned out followed by replacement of one-third of the water in each pool. Water salinity was measured every day and adjusted to the proper salinity as needed. Other water quality parameters were monitored 2-3 times a week with steady values of $\mathrm{pH}$ 7.5-7.9, total ammonia nitrogen of $<0.02 \mathrm{mg} \mathrm{L}^{-1}$ and temperature $26-28^{\circ} \mathrm{C}$. Photoperiod was $12 \mathrm{~h}: 12 \mathrm{~h}$ L:D throughout.

After 30 days of exposure to the three experimental conditions, the three turtles from each group were subjected to a $24 \mathrm{~h}$ fast, then anesthetized by cryo-anesthesia moving turtles to $-20^{\circ} \mathrm{C}$ for 0.5-1 h. Experimental animal procedures had the prior approval of the Animal Research Ethics Committee of Hainan Provincial Education Centre for Ecology and Environment, Hainan Normal University (permit no. HNECEE-2014-004). Following euthanasia, the liver of each 
105

106

107

108

individual was sampled and divided into two sections, flash frozen in liquid nitrogen, and stored at $-80^{\circ} \mathrm{C}$ until used for RNA extraction. One liver section was used for quantitative real-time PCR (qRT- PCR), and the other was mixed from each group of three turtles for RNA-seq analysis.

\section{Total RNA extraction, library construction and sequencing}

$$
\text { Extraction of total RNA from liver samples used TRIzol }{ }^{\circledR} \text { Reagent, following manufacturer's }
$$
instructions. Total RNA purity and concentration were determined using a NanoDrop 2000. The sequencing library was then constructed from high-quality RNA $\left(\mathrm{OD}_{260 / 280}=1.8-2.2\right.$, $\mathrm{OD}_{260 / 230} \geq 1.5, \mathrm{RIN} \geq 8.0,28 \mathrm{~S}: 18 \mathrm{~S} \geq 1.0,>10 \mu \mathrm{g}$ ). RNA-seq analysis was provided by Novel Bioinformatics Co., Ltd using the Sanger/Illumina method. Subsequently, cDNA libraries were made using the Hiseq4000 Truseq SBS Kit v3-HS using $5 \mu \mathrm{g}$ total RNA, following manufacturer's instructions. Poly(A) mRNA was isolated with Dyabeads (Life Technologies, USA), fragmented with RNaseIII and purified. The fragmented RNA was added and ligated with ion adaptor. Then double-stranded cDNA was synthesized and purified using magnetic beads. The molar concentration of the purified cDNA in each cDNA library was then quantified with a TBS-380 fluorometer using Picogreen. The paired-end RNA-seq library was sequenced with an Illumina HiSeq 4000. The RNA-Seq data were deposited in the NCBI with accession number GSE117354 (https://www.ncbi.nlm.nih.gov/geo/query/acc.cgi?acc=GSE117354).

\section{De novo assembly and annotation}


Raw reads were trimmed and quality controlled using SeqPrep (https://

github.com/jstjohn/SeqPrep) and Sickle (https://github.com/najoshi/sickle) using default

parameters. High-quality trimmed sequences were used for sequence assembly with Trinity

127

(https://github.com/trinityrnaseq/trinityrnaseq/wiki) (Grabherr et al., 2011). Q20, Q30, GC-

content and sequence duplication level of the clean data were all calculated. After that, All

assembled transcripts were identified by using BLASTX against the databases of NR (NCBI

non-redundant protein sequence), Swissprot (A manually annotated and reviewed protein

sequence database), Pfam (Protein family), GO (Gene ontology), COG (Clutsters of Orthologous

Groups of proteins) and KEGG (Kyoto Encyclopaedia of Genes and Genomes). The

BLAST2GO (http://www.blast2go.com/b2ghome) program (Conesa et al., 2005) was used to

obtain gene ontology (GO) annotations of unique assembled transcripts for describing biological

processes, cellular components, and molecular functions.

136

137

138

\section{Analysis of differential expression and functional enrichment}

Expression levels of transcripts were calculated as fragments per kilobase of exon per million mapped reads (FPKM). RNA-Seq by Expectation-Maximization (RSEM;

http://deweylab.biostat.wisc.edu/rsem/) was used to quantify gene transcripts, and DEGseq (http://www.bioconductor.org/packages/release/bioc/vignettes/DEGseq/inst/doc/DEGseq.pdf) was used to conduct differential expression analysis. The resulting $p$ values were adjusted using the Benjamini and Hochberg's approach for controlling the false discovery rate. Genes with an adjusted $p$ value $<0.05$ found by DEGseq were assigned as differentially expressed. GO 
144 145 146 147

enrichment analysis of the DEGs was implemented by the GOseqR packages based on Wallenius non-central hyper-geometric distribution (Xie et al., 2011), which can adjust for gene length bias in DEGs.

\section{Experimental validation by qRT-PCR}

Eighteen genes identified as significantly expressed from the GO terms related to osmotic regulation were selected to understand the gene expression levels in different groups, and also used for validation by qRT-PCR. Table 1 shows the specific primers used. TRIzol® Reagent (Invitrogen, Carlsbad, USA) was used to extract total RNA from liver, followed by reversetranscription using First-strand cDNA Synthesis Kit (Invitrogen, Carlsbad, US). The qRT-PCR for gene expression was analyzed by an Applied Biosystems 7500 Fast Real-Time PCR System in 96-well plates with a $20 \mu \mathrm{l}$ reaction volume containing $1 \times$ SYBR Green qPCR Master Mix, gene-specific forward and reverse primers $(0.4 \mu \mathrm{M})$ and cDNA $(8 \mathrm{ng})$. The cycling conditions were $95^{\circ} \mathrm{C}$ for $2 \mathrm{~min}$ followed by 40 cycles of $95^{\circ} \mathrm{C}$ for $5 \mathrm{~s}$ and $60^{\circ} \mathrm{C}$ for $30 \mathrm{~s}$. $\beta$-actin was chosen as the reference gene, as it was expressed in the three groups and unaffected under salinity stress, and relative fold changes were determined using Relative Expression Software Tool v.2009 based on the cycle threshold $(\mathrm{Ct})$ values generated by qRT-PCR. The mRNA expression levels were expressed as mean \pm standard error. Statistical analyses were conducted with SPSS 19.0. After testing the homogeneity of variance, statistical difference between treatments and controls were determined by one-way analysis of variance (ANOVA). LSD multiple comparison tests were carried out when the variances were homogeneous. 
164 Significant differences were set at $p<0.05$.

\section{RESULTS}

\section{Analysis of sequenced data quality}

Because we haven't got the genome of $T$. s. elegans yet, a transcriptome was used as a

reference to identify the differentially expressed genes induced by salinity exposure.

Therefore, a mixed RNA pool from the samples of the control and salinity treatment

groups was sequenced as the reference transcriptome. The data qualities from each sample

were shown in Table 2. A total of 157.21 million reads and 23.58 billion bases were

obtained from the liver transcriptome of T. s. elegans, including 50.68 million in $0 \mathrm{psu}$,

57.91 million in 5 psu and 48.62 million in 15 psu groups. After filtering low quality

sequences by, trimming sequencing adapters/poly-N and removing poor quality reads,

there were 152.52 million clean reads (97.02\% of raw reads) were retained including 48.92

million in 0 psu, 56.50 million in 5 psu and 47.10 million in 15 psu. Subsequently, 205138

unigenes with an average length of $620 \mathrm{bp}$ and N50 of $964 \mathrm{bp}$ were obtained by de novo

assembly. The largest and smallest unigenes were $22866 \mathrm{bp}$ and $201 \mathrm{bp}$, respectively

179 (Table 3).

\section{Annotation and differential expression of genes}

181 Putative functions of proteins encoded by the 205138 genes were predicted by NR, Pfam,

182 COG, Swissprot, GO and KEGG database. The results showed that there were $20458(9.97 \%)$, 
18320421 (9.95\%), 13362 (6.51\%), 10673 (5.2\%), 25438 (12.36\%), and 38651 (18.84\%) in Pfam,

184 KEGG, GO, COG, Swissprot and NR databases, respectively (Table 4).

185 By GO annotation, the genes up-regulated or down-regulated were divided into three

186 categories including biological process, cellular component and molecular function (Fig 1).

187 Among the category of biological process, the number of differentially expressed gene was

188 higher in the GO terms of cellular process, metabolic process, single-organism process and

189 biological regulation. Among the category of cellular component, the number of differentially

190 expressed gene was higher in the GO terms of cell, cell part, macromolecular complex, and

191 membrane. In relation to molecular function, the number of differentially expressed gene was

192 higher in the GO terms of binding, catalytic activity, and transporter activity. Moreover, there

193 was almost the same trend in the comparisons of 0 vs 5 psu, 0 vs 15 psu, and 5 vs 15 psu.

194 On the basis of criteria of two fold or greater change and Q of $p<0.05,3393$ unigenes were

195 identified as significant differentially expressed genes (DEGs), including 1019 (445 up-regulated

196 and 574 down-regulated) DEGs in 0 vs 5 psu, 1194 (526 up-regulated and 668 down-regulated)

197 DEGs in 0 vs 15 psu, and1180 (548 up-regulated and 632 down-regulated) DEGs in 5 vs 15 psu.

198 Many DEGs were classified into some dominant categories by GO enrichment analyses,

199 including the macromolecule metabolic process (52 DEGs), ion transport (35 DEGs), ion

200 transmembrane transport (24 DEGs) in biological process, and nucleic acid binding (37 DEGs),

201 oxidoreductase activity (35 DEGs), transporter activity (33 DEGs), and transmembrane

202

transporter activity (27 DEGs) in molecular function (Table 5). 
As for osmotic adjustment, there were 15 major GO terms related to osmotic function in

204

205

206

207

208

209

210

211

212

213

214

215

216

217

218

219

220

221

222

223

turtle liver in the comparison of 0 vs 5 psu (Table S1) and 12 in the comparison of 0 vs 15 psu

(Table S2). Based on GO enrichment analysis, a list of candidate genes involved in salinity

acclimation in T. s. elegans were identified. Many of these were identified as encoding proteins

involved in ion transport, energy production and conversion, and macromolecule metabolic

process including lipid, protein and carbohydrate.

Based on the annotation of DEGs, we selected ten genes related to ion regulation, five genes

related to energy production and conversion, five genes related lipid metabolism, eight genes

related amino acid metabolism and six genes related carbohydrate metabolism (Table 6). Among

the DEGs associated with ion regulation, five genes (adipocytokine, $A C D C$; insulin receptor-

related protein, INSRR; serine/threonine-protein kinase 32, STK32; salt-inducible kinase 1, SIK1;

potassium voltage-gated channel subfamily $\mathrm{H}$ member $5, \mathrm{KCNH5}$ ) were up-regulated in the

comparison of 0 vs 5 psu, and four genes (salt-inducible kinase 2, SIK2; SIK1;ACDC; STK32)

were up-regulated in the comparison of 0 vs $15 \mathrm{psu}$, and five genes $(S I K 1, S I K 2, S T K 33, A C D C$,

and solute carrier family 26 member 9, SLC26A9) were up-regulated in the comparison of 5 vs

15 psu. All of the five DEGs (cytochrome c oxidase subunit I, COX1; cytochrome c oxidase

subunit III, $C O X 3$; cytochrome b, $C Y T b$; F-ATPase protein 6, ATP6, and cytochrome P450 17A1,

$C Y P 17 A 1)$ associated with energy production and conversion showed up-regulation under

salinity stress, which indicated that there was a higher energy demand in response to salinity

exposure. In general, lipid and carbohydrate were the main sources of energy. As for five DEGs

associated with lipid metabolism, three DEGs (apolipoprotein E precursor, ApoE; coenzyme Q- 
224 binding protein, $C o Q 10$; high-density lipoprotein particle, $S A A$ ) increased with ambient salinity

225 increased, while one DEGs (alcohol dehydrogenase 4, $A D H 4$ ) showed down-regulation in the

226 comparison of 0 vs 5 psu and one DEGs (fatty acid desaturase 6, FADS6) down-regulation in the

227 comparison of 0 vs 15 psu. Among six DEGs related to carbohydrate metabolism, two DEGs

228 (hexokinase, $H K$ and lens fiber major intrinsic protein, $M I P$ ) increased with ambient salinity

229 increased, four DEGs (glucokinase, GCK; tagatose 1,6-diphosphate aldolase, LacD; L-gulono-

230 gamma-lactone oxidase, $G L O$ and ribulose bisphosphate carboxylase small chain, $R B C s$ )

231 decreased under salinity stress. In addition, six DEGs (ornithine decarboxylase antizyme 3,

232 OAZ3; glutamine synthetase, GLUL; asparaginase-like protein, $A S R G L$; L-amino-acid oxidase-

233 like, $L A A O$; sodium-dependent neutral amino acid transporter, $S L C 6 A 15 \mathrm{~s}$; amino acid permease,

$234 S L C 7 A 9$ ) related to amino acid metabolism showed up-regulation and two DEGs (tyrosine

235 aminotransferase, $T A T$ and argininosuccinate synthase, ASS1) showed down-regulation in the

236 comparison of 0 vs 5 psu, while four DEGs (OAZ3, GLUL, ASRGL, SLC7A9) showed up-

237 regulation and three DEGs ( $L A A O, T A T, A S S 1)$ showed down-regulation in the comparison of 0

238 vs 15 psu.

239 Verification of gene expression by SYBR Green qRT-PCR

240 Some genes related to ion transport, energy production and conversion and macromolecule

241 metabolic process mentioned above were selected for qRT-PCR analysis in order to validate the

242 differentially expressed genes that were identified by RNA-Seq and gain detailed quantitative

243 information on their differing expression patterns. As shown in Table 7, the mRNA expression

244 levels of $C O X 3, A T P 6$ and $C Y P 17 A 1$ related to energy production and conversion in the 5 psu 
group were almost 3.6-, 2.2- and 1.5-fold of the control respectively, while those in the 15 psu

group were almost 2.4-, 3.4- and 2.1-fold of the control respectively. In relation to ion transport,

247 the mRNA expression levels of STK32 and SIK1 in the 5 psu group were almost 3.6- and 2.1-

248 fold of the control respectively, while those in the15 psu group were almost 3.0- and 3.5-fold of

249 the control respectively. The mRNA expression levels of INSRR increased 2-fold in the 5 psu group and decreased 2.6-fold in the 15 psu group compared to the control, however, that of STK33 decreased 2.2- and 1.5-fold in the group of 5 psu and 15 psu compared to the control. As for macromolecular metabolism, the mRNA expression levels of $A P o E, C o Q 10, S A A, H K$, $G L U L$, and $A S R G L$ increased with ambient salinity increased. Especially for the genes of CoQ10 and $S A A$, the mRNA expression levels in the 15 psu group were almost 8.4- and 15.3-fold of the control respectively. However, the mRNA expression levels of $G C K$ and $A S S 1$ decreased with ambient salinity increased, and those in the group of 5 psu were almost 1.5- and 2.0-fold of the control, and those in the group of 15 psu were 3.7- and 9.7-fold of the control. The mRNA expression levels of FADS6 and TAT in the 5 psu group were lowest among the three groups, and decreased almost 2.3- and 3.6-fold compared to the control.

The qRT-PCR results were significantly correlated with the RNA-seq results with correlation coefficients of 0.744 in 0 vs 5 psu, 0.862 in 0 vs 15 psu groups and 0.748 in 5 vs 15 psu groups $(p<0.05)$ (Fig. S1). This provides strong evidence that RNA-Seq data can be a reliable indicator of the expression patterns of the hundreds of genes identified as differentially expressed in the current study. 
265

266

267

268

269

270

271

272

273

274

275

276

277

278

279

280

281

282

283

284

285

\section{DISCUSSION}

Osmoregulation in some aquatic animals can be a complex process because individuals must deal with fluctuating salinity levels in their natural habitats, often on a daily or seasonal basis. As

a normally freshwater species, the red-eared slider T. s. elegans, does not possess salt glands, and requires osmoregulation to survive when entering environments of higher salinity (e.g. brackish or estuarine water). The physiological research has shown that T. s. elegans can increase blood osmotic pressure by balancing the entry of $\mathrm{NaCl}$ with the decreased secretion of aldosterone, and accumulating urea and free amino acids in blood (Hong et al. 2014). In our study, many DEGs were classified into some dominant categories including the macromolecule metabolic process, ion transport and ion transmembrane transport in biological process, which provide a strong evidence for the physiological mechanism.

Under salinity stress, loss of water from the cells can cause cells shrink and potentially die. In this sense, ion regulation is important for a cell to balance osmotic change. KCNH5 (www. ncbi.nlm.nih.gov/gene/27133) and SCN1B (Qin et al., 2003) are involved in potassium/sodium voltage-gated ion channels and fluid balance that controls arterial blood pressure by altering blood electrolyte composition and/or volume. Natriuretic peptide A (NPPA) is well known to regulate body fluid levels and electrolytic homeostasis and has natriuretic, diuretic, and vasodilatory actions (Espiner et al., 2014). NPPA is highly expressed and associated with $\mathrm{H}_{2} \mathrm{O} / \mathrm{Na}^{+}$absorption and protein Ser/Thr phosphatases (Espiner et al. 2014). SIK acts to modulate adrenocortical function particularly in response to high plasma $\mathrm{Na}^{+}, \mathrm{K}^{+}, \mathrm{ACTH}$, or stress (Wang et al., 1999). SIK1 also has a role in steroidogenesis whereas SIK2 is implicated in 
gluconeogenesis regulation in liver; both belong to the AMPK (AMP-activated kinase)

287 subfamily of serine/threonine kinases (Berggreen et al., 2012). The AMPK is a crucial regulator of cellular energy levels (Hardie \& Ashford 2014) and under stress conditions that deplete ATP, AMPK action promotes ATP-producing catabolic pathways while inhibiting ATP-consuming anabolic functions (Rider et al., 2009; Rider et al., 2006). Transcripts of adiponectin (ACDC) were also enriched in liver under both salinity stresses and this hormone participates in the pathway of fatty acid oxidation by regulating AMPK (Chong et al., 2013). So, in our study, five genes $(A C D C, I N S R R, S T K 32, S I K 1, K C N H 5)$ were up-regulated in the comparison of 0 vs 5 psu, and three genes $(A C D C, S T K 32, S I K 2)$ were up-regulated in the comparison of 0 vs 15 psu, which suggested that $T$. s. elegans can adapt itself into saline environment by increasing the expression levels of genes related to ion regulation.

Genes associated with transporting molecules related to metabolic processes were also modulated in association with an up-regulation of genes involved in ATP energy production. As salinity level increases, acclimation of $T$. s. elegans to elevated salinity conditions requires investment of energy to maintain their homeostatic balance (Hong et al. 2014). In our study, the DEGs related to energy production and conversion including ATP6, COX1, COXIII, CYTb, and CYP17A1 increased with ambient salinity increased, which suggested that a requirement for more energy by T. s. elegans during raised salinity conditions. The result is associated with the ATP needed for the synthesis and operation of transport-related proteins that drive ion- and osmoregulatory processes (Lee et al., 2003). It is also documented that changes in components related to the glycolysis, fatty acid metabolism, and ATP production are often associated with 
307

308

309

310

311

312

313

314

315

316

317

318

319

320

321

322

323

324

325

326

327

raised salinity conditions in freshwater fish (Lavado et al., 2014; Tine et al., 2008). Our previous

study has shown that $T$. s. elegans increased serum glucose and triglyceride levels when

subjected to salinity stress (Shu et al., 2012). This study also indicated that salinity stress

influences glycolysis/gluconeogenesis and fatty acid metabolism-related genes. The mRNA

expressions of $H K$ and $M I P$ were increased, which suggested that utilization of glycogen might

be increased and more glucose might be used for energy expenditure under salinity exposure.

Moreover, the gene expressions of $A P o E, C o Q 10$, and $S A A$ were up-regulated while $A D H 4$ and

FADS6 were down-regulated, which suggested that the lipolysis increased and lipogenesis

decreased to produce more energy in response to salinity stress.

The ureogenesis is a strategy for diamondback terrapins (Malaclemys terrapin) that are

known to inhabit brackish water, and for the desert tortoise, Gopherus agassizii under

dehydration stress (Dantzler \& Schmidt-Nielsen 1966). The red-eared slider turtle, T. s. elegans,

can also increase urea content in plasma and tissues by synthesizing organic osmolytes (e.g. free

amino acids and urea) in order to provide a colligative defense against water loss (Hong et al.

2014). Some DEGs associated with cellular amino acid metabolism including GLUL, $A S R G L$,

$L A A O, S L C 6 A 15 \mathrm{~s}$ and $S L C 7 A 9$ were up-regulated in the comparison of 0 vs $5 \mathrm{psu}$, which

indicated that amino acid metabolism and transport were strengthened by salinity stress. The up-

regulated expression of GLUL showed the increase of glutamine synthetase. Glutamine is the

most prevalent amino acid in body fluids and muscle, is mainly transported by a $\mathrm{Na}^{+}$-dependent

neutral amino acid system, and its turnover rate exceeds those of other amino acids (Zander et al.,

2015). Glutamine is synthesized from the ATP-dependent conjugation of ammonia to glutamate, 
328

329

330

331

332

333

334

335

336

337

338

339

340

341

342

343

344

345

346

347

348

and is a well-known defense against ammonia (Cooper \& Plum 1987; Essexfraser et al., 2005).

When salinity returns to normal, glutamine pools can be utilized as precursors for a variety of important cell molecules (e.g. purines, pyrimidines, mucopolysaccharides) or, in the presence of glutaminase, glutamine can be deaminated for direct excretion of ammonia in the kidney or used for urea synthesis in liver before excretion. The accumulation of urea in response to high salinity can be due to both urea retention and elevated rates of urea synthesis via the ornithine-urea cycle, uricolysis of uric acid, or hydrolysis of arginine (Dépêche \& Schoffeniels 1975; Gordon \& Tucker 1965). OAZ3, involved in the ornithine-urea cycle, showed up-regulation under salinity exposure in this study, which suggested that ureogenesis may also be activated in response to hyperosmotic conditions in this species. Our result correlated well with studies in crab-eating frog (Fejervarya cancrivora), where its resistance to hyperosmotic environmental conditions is generally linked to the accumulation of urea in plasma and tissues, urea resulting from an upregulation of the hepatic urea synthesis machinery (Gordon \& Tucker 1965). Also, the striped catfish (Pangasianodon hypophthalmus) can counteract osmotic imbalance by triggering a regulatory volume increase, an internal process that initiates a net gain in osmolytes and/or water, increasing cell volume that re-establishes normal values and prevents further cell shrinkage (Nguyen et al., 2016).

The current study was designed not only to generate a catalogue of differentially expressed genes involved with salinity exposure, but also to allow the data to be integrated to identify the relationships on the adaptive response. Based on gene ontology information and from data in published studies, functional categories of differentially expressed genes were identified. 
349 Therefore, the potential interactions of the differentially expressed genes that responded to high

350 salinity in T. s. elegans are shown in Figure. 2. The pathways and processes that are targeted

351 provide us with numerous candidate genes for future investigations about the molecular

352 mechanisms that underlie high salinity tolerance.

\section{CONCLUSIONS}

354 In this study, we report the first transcriptome analysis of T. s. elegans under salinity stress.

When T. s. elegans was subjected with salinity exposure, 3393 unigenes in the liver were

identified as DEGs, which were classified into some dominant categories including

macromolecule metabolic process, ion transport, ion transmembrane transport in biological

process. And a list of candidate DEGs potentially involved in salinity acclimation in T. s. elegans

were identified into three kinds such as ion transport, energy production and conversion, and

macromolecule metabolic process including lipid, protein and carbonhydrate.

The genes related to macromolecule metabolic process (OAZ3, GLUL, ASRGL, LAAO,

SLC6A15s, SLC7A9, APoE, CoQ10, SAA, HK, and MIP), ion transport (KCNH5, STK32, SIK1,

and $A C D C$ ) and ATP synthesis (ATP6, $C O X 1, C O X 3, C Y T b$, and $C Y P 17 A 1)$ were up-regulated

by salinity stress, which indicated that $T$. s. elegans could adapt itself into salinity stress by

balancing the entry of $\mathrm{NaCl}$ and accumulating urea and free amino acids in blood in response to

osmotic pressure with higher ATP energy production. However, some genes related to

macromolecule metabolic process (ADH4, FADS6, LacD, GLO, RBCs, TAT, and ASS1) and ion 
370 that describe potential relationships and interactions among target genes to explain the molecular

371 pathways related to salinity responses in T. s. elegans.

\section{ACKNOWLEDGEMENTS}

373 We are grateful to Dr. Heidy Kikillus from Victoria University of Wellington, New Zealand for 374 revising a previous version of this manuscript.

\section{Data Availability}

376 The following information was supplied regarding data availability:

377 The raw data has been supplied as a Supplemental Dataset File

378 (https://www.ncbi.nlm.nih.gov/geo/query/acc.cgi?acc= GSE117354).

379

380 Table captions

381 Table 1 Sequences of primers for qRT-PCR validation

382 Table 2 Summary of Illumina expression short reads production and filtering

383 Table 3 Summary of de novo assembly results of illumina sequence data

384 Table 4 The functional annotation of unigenes

385 Table 5 Summary of GO term enrichment results on ion-regulation and macromolecular

386 metabolism in T. s. elegans under salinity stress.

387 Table 6 DEGs related to energy production and conversion, macromolecule metabolic process,

388 and ion transport in the liver of T. s. elegans

389 Table 7 The expression levels of some genes in relation to osmotic adjustment in the liver of T. s.

390 elegans by qRT-PCR 
391

392

393

394

395

396

397

398

399

400

401

402

403

404

405

406

407

408

409

410

411

412

413

414

415

416

417

418

419

420

421

422

423

424

\section{Supplemental Information}

Table S1 Major GO terms related to osmotic regulation in 0 vs 5 psu groups

Table S2 Major GO terms related to osmotic regulation in 0 vs 15 psu groups

Fig $\mathrm{S} 1$ The relative fold changes $\left(\log _{2} \mathrm{FC}\right)$ of RNA-seq and qRT-PCR results in the comparison

of 0 vs 5 psu (A), and 0 vs 15 psu (B). The expression levels of selected genes were each

normalized to that of the $\beta$-actin gene.

\section{References}

Berggreen C, Henriksson E, Jones HA, Morrice N, and Göransson O. 2012. cAMP-elevation mediated by $\beta$-adrenergic stimulation inhibits salt-inducible kinase (SIK) 3 activity in adipocytes. Cellular Signalling 24:1863 DOI 10.1016/j.cellsig.2012.05.001

Charmantier G, Charmantierdaures M, Waddy SL, and Aiken DE. 2011. Salinity tolerance and osmoregulation in the Nemertean Pseudocarcinone. Canadian Journal of Fisheries \& Aquatic Sciences 48:209-214 DOI 10.1139/f91-028.

Chong D, Li L, Su YC, Xiang RL, Xin C, Yu HK, Li SL, Wu LL, and Yu GY. 2013. Adiponectin increases secretion of rat submandibular gland via adiponectin receptorsmediated AMPK signaling. Plos One 8:e63878 DOI 10.1371/journal.pone.0063878.

Conesa A, Götz S, Garcíagómez JM, Terol J, Talón M, and Robles M. 2005. Blast2GO: A universal annotation and visualization tool in functional genomics research. Application note 21:3674-3676.

Cooper AJ, and Plum F. 1987. Biochemistry and physiology of brain ammonia. Physiological Reviews 67:440-519 DOI 10.1152/physrev.1987.67.2.440.

Dépêche J, and Schoffeniels E. 1975. Changes in electrolytes, urea and free amino acids of Poecilia reticulata embryos following high salinity adaptation of the viviparous female. Biochemical Systematics \& Ecology 3:111-119 DOI 10.1016/0305-1978(75)90050-2

Dantzler WH, and Schmidt-Nielsen B. 1966. Excretion in fresh-water turtle (Pseudemys scripta) and desert tortoise (Gopherus agassizii). American Journal of Physiology 210:198-210 DOI 10.1152/ajplegacy.1966.210.1.198.

Espiner EA, Dalrymple-Alford JC, Prickett TCR, Alamri Y, and Anderson TJ. 2014. Ctype natriuretic peptide in Parkinson's disease: reduced secretion and response to deprenyl. Journal of Neural Transmission 121:371-378 DOI 10.1007/s00702-013-1123-9.

Essexfraser PA, Steele SL, Bernier NJ, Murray BW, Stevens ED, and Wright PA. 2005. Expression of four glutamine synthetase genes in the early stages of development of rainbow trout (Oncorhynchus mykiss) in relationship to nitrogen excretion. Journal of Biological Chemistry 280:20268-20273 DOI 10.1074/jbc.M412338200. 
425 Gordon MS, and Tucker VA. 1965. Osmotic regulation in tadpoles of crab-eating frog (Rana

426 cancrivora). Deep Sea Research Part B Oceanographic Literature Review 42:437-445.

Grabherr MG, Haas BJ, Yassour M, Levin JZ, Thompson DA, Amit I, Adiconis X, Fan L, Raychowdhury R, and Zeng Q. 2011. Full-length transcriptome assembly from RNASeq data without a reference genome. Nature Biotechnology 29:644-652 DOI 10.1038/nbt.1883.

Hardie DG, and Ashford ML. 2014. AMPK: regulating energy balance at the cellular and whole body levels. Physiology 29:99-107 DOI:10.1152/physiol.00050.2013

Hong M, Zhang K, Shu C, Xie D, and Shi H. 2014. Effect of salinity on the survival, ions and urea modulation in red-eared slider(Trachemys scripta elegans). Asian Herpetological Research 5:128-136 DOI 10.3724/SP.J.1245.2014.00128.

Lavado R, Aparicio-Fabre R, and Schlenk D. 2014. Effects of salinity acclimation on the expression and activity of phase I enzymes (CYP450 and FMOs) in coho salmon (Oncorhynchus kisutch). Fish Physiol Biochem 40:267-278 DOI 10.1007/s10695-0139842-2

Lee T, Feng S, Lin C, Hwang Y, Huang C, and Hwang P. 2003. Ambient salinity modulates the expression of sodium pumps in branchial mitochondria-rich cells of mozambique tilapia, Oreochromis mossambicus. Zoological Science 20:29-36 DOI 10.1016/S00220981(02)00597-X.

Li ZH, Xu H, Zheng W, Lam SH, and Gong Z. 2013. RNA-Sequencing analysis of TCDDInduced responses in zebrafish liver reveals high relatedness to in vivo mammalian models and conserved biological pathways. Plos One 8:e77292 DOI 10.1371/journal.pone.0077292.

Liu D, Shi H, Liu Y, Wng J, Gong S, Wang J, and Shen L. 2011. The investigation of the distribution of red ear turtle in China. Bulletin of Biology 46:18-21

Luiselli L, Capula M, Capizzi D, Filippi E, Jesus VT, and Anibaldi C. 1997. Problems for conservation of pond Turtles (Emys orbicularis) in central Italy: is the introduced redeared turtle (Trachemys scripta elegans) a serious threat? Chelonian Conservation \& Biology 2:417-419

Lushchak VI. 2011. Environmentally induced oxidative stress in aquatic animals. Aquatic Toxicology 101:13-30 DOI 10.1016/j.aquatox.2010.10.006.

Martins RA, Assalim AM, and Molina FDB. 2014. The presence of the red-eared slider, Trachemys scripta elegans (Wied, 1838) (Testudines, Emydidae), an invasive species, in the Paraibuna river basin, Southeastern Brazil. Herpetology Notes 7:437-441

McNamara JC, Rosa JC, Greene LJ, and Augusto A. 2004. Free amino acid pools as effectors of osmostic adjustment in different tissues of the freshwater shrimp Macrobrachium olfersii (crustacea, decapoda) during long-term salinity acclimation. Marine \& Freshwater Behaviour \& Physiology 37:193-208 DOI 10.1080/10236240400006208.

Mittermeier RA, Dijk PPV, Rhodin AGJ, and Nash SD. 2015. Turtle Hotspots: an analysis of the occurrence of tortoises and freshwater turtles in biodiversity hotspots, high- 
466

467

468

469

470

471

472

473

474

475

476

477

478

479

480

481

482

483

484

485

486

487

488

489

490

491

492

493

494

495

496

497

498

499

500

501

502

503

504

505

506

biodiversity wilderness areas, and turtle priority areas. Chelonian Conservation \& Biology 14:2-10 DOI 10.2744/ccab-14-01-2-10.1.

Nguyen TV, Jung H, Nguyen TM, Hurwood D, and Mather P. 2016. Evaluation of potential candidate genes involved in salinity tolerance in striped catfish (Pangasianodon hypophthalmus) using an RNA-Seq approach. Mar Genomics 25:75-88 DOI 10.1016/j.margen.2015.11.010

Qin N, D'Andrea MR, Lubin ML, Shafaee N, Codd EE, and Correa AM. 2003. Molecular cloning and functional expression of the human sodium channel $\beta 1 \mathrm{~B}$ subunit, a novel splicing variant of the $\beta 1$ subunit. Febs Journal 270:4762-4770 DOI 10.1046/j.14321033.2003.03878.x.

Rider MH, Hussain N, Dilworth SM, and Storey KB. 2009. Phosphorylation of translation factors in response to anoxia in turtles, Trachemys scripta elegans: role of the AMPactivated protein kinase and target of rapamycin signalling pathways. Molecular \& Cellular Biochemistry 332:207-213 DOI 10.1007/s11010-009-0193-3.

Rider MH, Hussain N, Horman S, Dilworth SM, and Storey KB. 2006. Stress-induced activation of the AMP-activated protein kinase in the freeze-tolerant frog Rana sylvatica. Cryobiology 53:297-309 DOI 10.1016/j.cryobiol.2006.08.001.

Shu CH, Zhang K, Hong ML, Xie D, Liu QC, and Shi HT. 2012. Effect of salinity stress on Trachemys scripta elegans growth and blood biochemical ingredient. Sichuan Journal of Zoology 31:912-916.

Smith S, Bernatchez L, and Beheregaray LB. 2013. RNA-seq analysis reveals extensive transcriptional plasticity to temperature stress in a freshwater fish species. Bmc Genomics 14:375 DOI 10.1186/1471-2164-14-375.

Thompson J, Franck L, and Valverde R. 2011. Effects of salinity on the endocrine stress response of Trachemys scripta in the lake Pontchartrain Basin [C]. SICB 2011 Annual Meeting Abstracts: 257.

Tine M, de Lorgeril J, D'Cotta H, Pepey E, Bonhomme F, Baroiller JF, and Durand JD. 2008. Transcriptional responses of the black-chinned tilapia Sarotherodon melanotheron to salinity extremes. Mar Genomics 1:37-46 DOI 10.1016/j.margen.2008.06.001.

Wang X, Teng M, Wang G, Zhao Y, Han X, Feng W, Li L, Sanford J, and Liu Y. 2009. xIPseq Platform: An integrative framework for high-throughput sequencing data analysis. Ohio Collaborative Conference on Bioinformatics. 26-31. DOI 10.1109/OCCBIO.2009.20.

Wang ZN, Takemori H, Halder SK, Nonaka Y, and Mitsuhiro O. 1999. Cloning of a novel kinase (SIK) of the SNF1/AMPK family from high salt diet-treated rat adrenal. Febs Letters 453:135-139 DOI 10.1016/S0014-5793(99)00708-5.

Wright PA, Campbell A, Morgan RL, Rosenberger AG, and Murray BW. 2004. Dogmas and controversies in the handling of nitrogenous wastes: expression of arginase Type I and II genes in rainbow trout: influence of fasting on liver enzyme activity and mRNA levels in juveniles. Journal of Experimental Biology 207:2033-2042 DOI 10.1242/jeb.00901. 
507 Xia JH, Liu P, Liu F, Lin G, Sun F, Tu R, and Yue GH. 2013. Analysis of stress-responsive

508

509

510

511

512

513

514

515

516

517

518 transcriptome in the intestine of Asian seabass (Lates calcarifer) using RNA-Seq: Lockheed Palo Alto . Research Laboratory 20 :865-878 DOI 10.1093/dnares/dst022.

Xie C, Mao X, Huang J, Ding Y, Wu J, Dong S, Kong L, Gao G, Li CY, and Wei L. 2011. KOBAS 2.0: a web server for annotation and identification of enriched pathways and diseases. Nucleic Acids Research 39:316-322 DOI 10.4049/jimmunol.174.12.7497.

Yancey PH. 1985. Organic Osmotic Effectors in Cartilaginous Fishes: Springer Berlin Heidelberg 424-436.

Yang J, and Shi H. 2014. Home range of Trachemys scripta elegans in brackish water of Nandu river, Hainan Island, China. Sichuan Journal of Zoology 33:685-688.

Zander C, Zhang Z, Albers T, and Grewer C. 2015. Amino Acid Transporters and Glutamine: Springer New York. pp 21-36. 


\section{Table 1 (on next page)}

Table 1 Sequences of primers for qRT-PCR validation 
Table 1 Sequences of primers for $q R T-P C R$ validation

\begin{tabular}{|c|c|c|c|}
\hline Gene & Forward primer (5' to $\left.3^{\prime}\right)$ & Reserse primer (5' to $\left.3^{\prime}\right)$ & Product length (bp) \\
\hline$C O X 3$ & TCACTTGAGCCCACCATAGC & AGAGCCGTACACACCATCAG & 155 \\
\hline ATP6 & CTTGATGCCCTCTTCCCGTG & TTCCTCGTTCTCCACAGCCT & 145 \\
\hline CYP17A1 & GATCGGCTTCGAGAGACACC & GGATCAGCAGAGGGGAGACA & 110 \\
\hline$A P o E$ & GTCTGGAGCGGGCTTAGTAG & CATTCCCAGGTCTCCCACAG & 117 \\
\hline $\operatorname{CoQ} 10$ & GCGAGTGCTGGGCTACT & TGAGCCCTTTGCGGTAGG & 119 \\
\hline$S A A$ & TCTAGGCGCTGGGGATATGT & CCACTAATGCCATCCTGCCA & 180 \\
\hline FADS6 & GCTGCCATACAACGAGGACT & AGCCCTATGTCTTGCTGTCG & 146 \\
\hline$H K$ & TAAAGGCGTAACCAGGCTGC & AATCGCACGTCAGAGTCAGG & 126 \\
\hline$G C K$ & CGGGAACTGCTGAAATGCTC & GAATGTGAAGCCCAGAGGCA & 104 \\
\hline$G L U L$ & GTTGCCACACCAACTTCAGC & AAGCGCGGATATGGTACTGG & 111 \\
\hline$A S R G L$ & TAGCACCTGTTCCAGTGAGC & GCTGTGTTTGATGCAGGTCA & 193 \\
\hline$T A T$ & CATCCACCAGCGACTCCAAG & CATCCTGGTGCCAAGACCTG & 137 \\
\hline$A S S 1$ & CGGGCTGTACCAGAAACCAT & GGGACCATCCTGTACCATGC & 129 \\
\hline STK32 & TCCAGTGCTAATGCCAGCTC & TGGAACACCCCTTCCTGGTT & 172 \\
\hline SIK1 & TGGTGTGGTGCTGTATGTCC & TCCACAACTAGCATCCGTCG & 156 \\
\hline SIK2 & GCTGGTCCTAGACCCATCCA & GAAGGCTCGTTCTCCTGTCC & 123 \\
\hline INSRR & CCGAGTACCGTGATCTGCTC & GGCAGCTCCACATCTACCAC & 127 \\
\hline STK33 & AGGCAGTTTTGGGGTGGTAA & TAAGATGCTCACCTCCCGTTC & 130 \\
\hline$\beta$-actin & GCACCCTGTGCTGCTTACA & CACAGTGTGGGTGACACCAT & 190 \\
\hline
\end{tabular}




\section{Table 2 (on next page)}

Table 2 Summary of Illumina expression short reads production and filtering 
Table 2 Summary of Illumina expressed short reads production and filtering

\begin{tabular}{llllllll} 
& Groups & Total_Reads & Total_Base & Error\% & Q20\% & Q30\% & GC\% \\
\hline \multirow{2}{*}{ Raw } & $0 \mathrm{psu}$ & 50681398 & 7602209700 & 0.0126 & 96.31 & 92.31 & 49.34 \\
data & $5 \mathrm{psu}$ & 57912616 & 8686892400 & 0.0121 & 96.72 & 92.87 & 49.18 \\
& $15 \mathrm{psu}$ & 48616356 & 7292453400 & 0.0129 & 96.21 & 91.98 & 49.93 \\
\hline \multirow{2}{*}{ Clean } & $0 \mathrm{psu}$ & 48918412 & 7157032240 & 0.0104 & 98.29 & 95.12 & 49.19 \\
data & $5 \mathrm{psu}$ & 56498176 & 8281257833 & 0.0103 & 98.34 & 95.18 & 49.09 \\
& $15 \mathrm{psu}$ & 47101028 & 6881004183 & 0.0107 & 98.17 & 94.77 & 49.83 \\
\hline
\end{tabular}

1 


\section{Table 3 (on next page)}

Table 3 Summary of de novo assembly results of illumina sequence data 
Table 3 Summary of de novo assembly results of Illumina sequence data

\begin{tabular}{lcc}
\multicolumn{1}{c}{ Type } & unigene & transcripts \\
\hline Total sequence number & 205138 & 244815 \\
Total sequence base & 127206404 & 185942194 \\
Percent GC & 46.09 & 46.65 \\
Largest & 22866 & 22866 \\
Smallest & 201 & 201 \\
Average & 620.1 & 759.52 \\
N50 & 964 & 1535 \\
N90 & 249 & 268 \\
\hline
\end{tabular}

2 


\section{Table 4(on next page)}

Table 4 The functional annotation of unigenes 


\begin{tabular}{lll}
\multicolumn{2}{l}{ Table 4 Functional annotation of the Trachemys scripta elegans transcriptome } \\
Annotated Database & Number of Unigenes & Precent(\%) \\
\hline Pfam & 20458 & 9.97 \\
KEGG & 20421 & 9.95 \\
GO & 13362 & 6.51 \\
COG & 10673 & 5.2 \\
Swissprot & 25438 & 12.36 \\
NR & 38651 & 18.84 \\
Total & 205138 & 1 \\
\hline
\end{tabular}

1 


\section{Table 5 (on next page)}

Table 5 Summary of GO term enrichment results on ion-regulation and macromolecular metabolism in $T$. s. elegans under salinity stress 
Table 5 Summary of GO term enrichment results on ion-regulation and macromolecular metabolism in $T$. s. elegans under salinity stress

\begin{tabular}{|c|c|c|c|c|}
\hline GO ID & Description & $\begin{array}{l}\text { Ratio in } \\
\text { study }\end{array}$ & Ratio in pop & $\begin{array}{l}p \text {-value } \\
\text { (FDR) }\end{array}$ \\
\hline GO:0006091 & $\begin{array}{l}\text { generation of precursor metabolites } \\
\text { and energy }\end{array}$ & $17 / 357$ & $119 / 13362$ & 4.33E-05 \\
\hline GO:0009060 & aerobic respiration & $7 / 357$ & $17 / 13362$ & 0.0003 \\
\hline GO:0045333 & cellular respiration & $7 / 357$ & $19 / 13362$ & 0.0004 \\
\hline GO:0015980 & $\begin{array}{l}\text { energy derivation by oxidation of } \\
\text { organic compounds }\end{array}$ & $8 / 357$ & $40 / 13362$ & 0.0065 \\
\hline GO:0034220 & ion transmembrane transport & $24 / 357$ & $336 / 13362$ & 0.0081 \\
\hline GO:0098660 & inorganic ion transmembrane transport & $18 / 357$ & $209 / 13362$ & 0.0081 \\
\hline GO:0098655 & cation transmembrane transport & $18 / 357$ & $210 / 13362$ & 0.0081 \\
\hline GO:0006119 & oxidative phosphorylation & $4 / 357$ & $7 / 13362$ & 0.0081 \\
\hline GO:1902991 & $\begin{array}{l}\text { regulation of amyloid precursor protein } \\
\text { catabolic process }\end{array}$ & $3 / 357$ & $3 / 13362$ & 0.0081 \\
\hline GO:1902992 & $\begin{array}{l}\text { negative regulation of amyloid } \\
\text { precursor protein catabolic process }\end{array}$ & $3 / 357$ & $3 / 13362$ & 0.0081 \\
\hline GO:1902430 & $\begin{array}{l}\text { negative regulation of beta-amyloid } \\
\text { formation }\end{array}$ & $3 / 357$ & $3 / 13362$ & 0.0081 \\
\hline GO:1902003 & regulation of beta-amyloid formation & $3 / 357$ & $3 / 13362$ & 0.0081 \\
\hline GO:0006811 & ion transport & $35 / 357$ & $623 / 13362$ & 0.0109 \\
\hline GO:0006812 & cation transport & $23 / 357$ & $335 / 13362$ & 0.0114 \\
\hline GO:1902600 & hydrogen ion transmembrane transport & $10 / 357$ & $77 / 13362$ & 0.0117 \\
\hline GO:1900221 & regulation of beta-amyloid clearance & $3 / 357$ & $4 / 13362$ & 0.0177 \\
\hline GO:0098662 & $\begin{array}{l}\text { inorganic cation transmembrane } \\
\text { transport }\end{array}$ & $15 / 357$ & $176 / 13362$ & 0.0178 \\
\hline GO:0050773 & regulation of dendrite development & $6 / 357$ & $28 / 13362$ & 0.0184 \\
\hline GO:0015672 & monovalent inorganic cation transport & $14 / 357$ & $171 / 13362$ & 0.0410 \\
\hline GO:0005576 & extracellular region & $18 / 357$ & $220 / 13362$ & 0.0097 \\
\hline GO:0044463 & cell projection part & $16 / 357$ & $206 / 13362$ & 0.0281 \\
\hline GO:0015078 & $\begin{array}{l}\text { hydrogen ion transmembrane } \\
\text { transporter activity }\end{array}$ & $11 / 357$ & $76 / 13362$ & 0.0047 \\
\hline GO:0015077 & $\begin{array}{l}\text { monovalent inorganic cation } \\
\text { transmembrane transporter activity }\end{array}$ & $16 / 357$ & $176 / 13362$ & 0.0083 \\
\hline GO:0022890 & $\begin{array}{l}\text { inorganic cation transmembrane } \\
\text { transporter activity }\end{array}$ & $18 / 357$ & $236 / 13362$ & 0.0167 \\
\hline GO:0008324 & $\begin{array}{l}\text { cation transmembrane transporter } \\
\text { activity }\end{array}$ & $20 / 357$ & $293 / 13362$ & 0.0268 \\
\hline GO:1902991 & $\begin{array}{l}\text { regulation of amyloid precursor protein } \\
\text { catabolic process }\end{array}$ & $3 / 357$ & $3 / 13362$ & 0.0081 \\
\hline
\end{tabular}




\begin{tabular}{lllll} 
GO:1902992 & $\begin{array}{l}\text { negative regulation of amyloid } \\
\text { precursor protein catabolic process }\end{array}$ & $3 / 357$ & $3 / 13362$ & 0.0081 \\
GO:0034364 & high-density lipoprotein particle & $5 / 357$ & $13 / 13362$ & 0.0081 \\
GO:0032994 & protein-lipid complex & $5 / 357$ & $16 / 13362$ & 0.0129 \\
GO:1990777 & lipoprotein particle & $5 / 357$ & $16 / 13362$ & 0.0129 \\
GO:0034358 & plasma lipoprotein particle & $5 / 357$ & $16 / 13362$ & 0.0129 \\
\hline
\end{tabular}

1 GO names were retained only from GO terms of levels $>2$ 


\section{Table 6(on next page)}

Table 6 DEGs related to energy production and conversion, macromolecule metabolic process, and ion transport in the liver of $T$. s. elegans 
Table 6 DEGs related to energy production and conversion, macromolecule metabolic process, and ion transport in the liver of $T$. s. elegans

Unigene ID Description

c198757_g1

cytochrome c oxidase subunit I $(C O X 1)$

c205807_g1

c184332_g1

cytochrome c oxidase subunit III ( $C O X 3)$

c168776_g1

cytochrome b $(C Y T b)$

c122818_g1

F-ATPase protein 6 (ATPO)

cytochrome P450 17A1 (CYP17A1)

DEGs related to lipid metabolic process

c183562_g1 apolipoprotein E precursor ( $A P O E)$

c108401_g1

coenzyme Q-binding protein ( $C O Q 10)$

c106996_g1

high-density lipoprotein particle $(S A A)$

c101752_g1

alcohol dehydrogenase $4(A D H 4)$

c5275_g1

fatty acid desaturase 6 (FADS6)

DEGs related to carbohydrate metabolic process

$\begin{array}{ll}\text { c184502_g1 } & \text { hexokinase-1 }(H K) \\ \text { c141564_g1 } & \text { lens fiber major intrinsic protein }(M I P) \\ \text { c121000_g1 } & \text { glucokinase }(G C K) \\ \text { c198426_g1 } & \text { tagatose 1,6-diphosphate aldolase }(L a c D) \\ \text { c139209_g1 } & \text { L-gulono-gamma-lactone oxidase }(G L O) \\ \text { c44501_g1 } & \text { ribulose bisphosphate carboxylase small chain } \\ & (R B C s)\end{array}$

DEGs related to amino acid metabolic process

c198734

c184545_g1

ornithine decarboxylase antizyme 3 (OAZ3)

glutamine synthetase (GLUL)

c197142_g1

asparaginase-like protein $1 \mathrm{~b}(A S R G L)$

c117856_g3

c169209_g1

c103361_g1

L-amino-acid oxidase-like ( $L A A O)$

sodium-dependent neutral amino

transporter B $(S L C 6 A 15 s)$

c108456_g1

amino acid permease (SLC7A9)

tyrosine aminotransferase (TAT)

c99414_g1

argininosuccinate synthase (ASS1)

\section{DEGs related to ion transport}

$\begin{array}{ll}\text { c182997_g1 } & \begin{array}{l}\text { potassium voltage-gated channel subfamily H } \\ \text { member } 5(\text { KCNH5) }\end{array} \\ \text { c121057_g1 } & \text { serine/threonine-protein kinase } 32 \text { (STK32) } \\ \text { c121806_g3 } & \text { salt-inducible kinase 1 (SIK1) } \\ \text { c123793_g3 } & \text { salt-inducible kinase 2 (SIK2) } \\ \text { c114797_g4 } & \text { adiponectin }(A C D C)\end{array}$

\begin{tabular}{lll}
$\log _{2}$ & $\log _{2}$ & $\log _{2}$ \\
$(5 / 0 \mathrm{psu})$ & $(15 / 0 \mathrm{psu})$ & $(15 / 5 \mathrm{psu})$ \\
\hline
\end{tabular}

$7.03-7.14$

$5.79 \quad 5.57$

$6.37 \quad 6.51$

$7.93 \quad 8.41$

$\begin{array}{lll}0.81 & 1.63 & 0.82\end{array}$

0.67

$4.59 \quad 4.18 \quad-0.40$

$\begin{array}{lll}2.51 & 3.44 & 0.93\end{array}$

$\begin{array}{lll}1.24 & 4.13 & 2.89\end{array}$

$\begin{array}{lll}-3.8 & - & 3.81\end{array}$

$\begin{array}{lll}-3.38 & -1.54 & 1.85\end{array}$

$\begin{array}{lll}4.49 & 5.22 & 0.73\end{array}$

$3.37 \quad 3.75$

$-0.22-1.94$

$-1.85$

$-5.38 \quad-5.12$

$-5.38 \quad-5.12$

$-4.38 \quad-4.12$

$\begin{array}{lll}6.28 & 7.00 & 0.72\end{array}$

$\begin{array}{lll}4.03 & 4.3 & 0.26\end{array}$

$\begin{array}{lll}4.49 & 4.96 & 0.47\end{array}$

$\begin{array}{lll}1.62 & -2.06 & -3.68\end{array}$

$3.59-1.54$

$\begin{array}{lll}1.78 & 5.72 & 3.93\end{array}$

$\begin{array}{lll}-1.72 & -1.41 & 0.31\end{array}$

$-0.69-1.1 \quad-0.41$

$3.5-3.5$

$1.95 \quad 1.80$

$\begin{array}{lll}1.23 & 2.20 & 0.97\end{array}$

$\begin{array}{lll}- & 0.27 & 0.40\end{array}$

$\begin{array}{lll}0.60 & 2.12 & 1.52\end{array}$ 


\begin{tabular}{lllll} 
c119528_g1 & insulin receptor-related protein (INSRR) & 0.30 & -1.70 & -2.00 \\
c95283_g1 & serine/threonine-protein kinase 33(STK33) & -1.5 & -0.65 & 0.85 \\
c58533_g1 & sodium channel subunit beta-1 (SCN1B) & -5.31 & -5.31 & - \\
c94169_g1 & natriuretic peptides A-like (NPPA) & -5.72 & -5.72 & - \\
c95302_g1 & solute carrier family 26 member 9 (SLC26A9) & -3.55 & -0.44 & 3.11 \\
\hline
\end{tabular}

1 Note: The values above zero show up-regulation of gene expression, while the values below zero show down-

2 regulation. "-" means that the level of gene expression is so low that it could not be detected. 


\section{Table 7 (on next page)}

Table 7 The expression levels of some genes in relation to osmotic adjustment in the liver of $T$. s. elegans by qRT-PCR 
Table 7 The expression levels of some genes in relation to osmotic adjustment in the liver of $T$. $s$. elegans by qRT-PCR

\begin{tabular}{|c|c|c|c|c|}
\hline Unigene ID & Description & Control & 5 psu & 15 psu \\
\hline \multicolumn{5}{|c|}{ Genes related to energy production and conversion } \\
\hline c205807_g1 & cytochrome c oxidase subunit III (COX3) & $1.01 \pm 0.06^{\mathrm{c}}$ & $3.57 \pm 0.27$ a & $2.40 \pm 0.29^{b}$ \\
\hline c168776_g1 & F-ATPase protein 6 (ATPO) & $1.09 \pm 0.10^{\mathrm{c}}$ & $2.42 \pm 0.09^{b}$ & $3.67 \pm 0.21^{\mathrm{a}}$ \\
\hline c122818_g1 & cytochrome P450 17A1 (CYP17A1) & $2.13 \pm 0.11^{\mathrm{c}}$ & $3.15 \pm 0.22^{b}$ & $4.46 \pm 0.38^{\mathrm{a}}$ \\
\hline \multicolumn{5}{|c|}{ Genes related to lipid metabolic process } \\
\hline c183562_g1 & apolipoprotein $\mathrm{E}$ precursor $(A P o E)$ & $0.86 \pm 0.06^{\mathrm{c}}$ & $2.77 \pm 0.12^{\mathrm{a}}$ & $1.80 \pm 0.13^{b}$ \\
\hline c108401_g1 & coenzyme Q-binding protein $(C o Q 10)$ & $0.64 \pm 0.08^{c}$ & $2.66 \pm 0.17^{b}$ & $5.39 \pm 0.23^{\mathrm{a}}$ \\
\hline c106996_g1 & high-density lipoprotein particle $(S A A)$ & $0.48 \pm 0.06^{\mathrm{c}}$ & $1.18 \pm 0.08^{b}$ & $7.32 \pm 0.27^{\mathrm{a}}$ \\
\hline c5275_g1 & fatty acid desaturase 6 (FADS6) & $2.23 \pm 0.27^{\text {a }}$ & $0.97 \pm 0.23^{b}$ & $1.37 \pm 0.13^{b}$ \\
\hline \multicolumn{5}{|c|}{ Genes related to carbohydrate metabolic process } \\
\hline c184502_g1 & hexokinase-1 $(H K)$ & $1.37 \pm 0.09^{\mathrm{c}}$ & $2.35 \pm 0.21^{b}$ & $3.27 \pm 0.22^{\mathrm{a}}$ \\
\hline c121000_g1 & glucokinase $(G C K)$ & $1.79 \pm 0.07^{\mathrm{a}}$ & $1.19 \pm 0.22^{b}$ & $0.48 \pm 0.05^{\mathrm{c}}$ \\
\hline \multicolumn{5}{|c|}{ Genes related to amino acid metabolic process } \\
\hline c184545_g1 & glutamine synthetase $(G L U L)$ & $1.82 \pm 0.14^{\mathrm{c}}$ & $5.10 \pm 0.23^{b}$ & $6.00 \pm 0.19^{\mathrm{a}}$ \\
\hline c197142_g1 & asparaginase-like protein $1 \mathrm{~b}(A S R G L)$ & $1.01 \pm 0.05^{b}$ & $1.64 \pm 0.17^{\mathrm{a}}$ & $1.94 \pm 0.31^{\mathrm{a}}$ \\
\hline c108456_g1 & tyrosine aminotransferase $(T A T)$ & $3.37 \pm 0.17^{\text {a }}$ & $0.93 \pm 0.03^{\mathrm{c}}$ & $1.38 \pm 0.06^{\mathrm{b}}$ \\
\hline c99414_g1 & argininosuccinate synthase ( $A S S 1)$ & $5.16 \pm 0.29^{\mathrm{a}}$ & $2.59 \pm 0.20^{b}$ & $0.53 \pm 0.07^{\mathrm{c}}$ \\
\hline \multicolumn{5}{|c|}{ Genes related to ion transport } \\
\hline c121806_g3 & salt-inducible kinase 1 (SIK1) & $1.19 \pm 0.13^{\mathrm{c}}$ & $2.46 \pm 0.31^{b}$ & $4.16 \pm 0.15^{\mathrm{a}}$ \\
\hline c123793_g3 & salt-inducible kinase 2 (SIK2) & $1.06 \pm 0.15^{\mathrm{a}}$ & $0.85 \pm 0.09^{a}$ & $1.13 \pm 0.10^{\mathrm{a}}$ \\
\hline c119528_g1 & insulin receptor-related protein (INSRR) & $2.04 \pm 0.18^{b}$ & $4.13 \pm 0.26^{\mathrm{a}}$ & $0.78 \pm 0.13^{\mathrm{c}}$ \\
\hline c121057_g1 & serine/threonine-protein kinase 32 (STK32) & $1.48 \pm 0.16^{\mathrm{c}}$ & $5.39 \pm 0.24^{\mathrm{a}}$ & $4.49 \pm 0.33^{b}$ \\
\hline c95283_g1 & serine/threonine-protein kinase 33 (STK33) & $3.93 \pm 0.37^{\text {a }}$ & $1.79 \pm 0.16^{\mathrm{b}}$ & $2.57 \pm 0.23^{b}$ \\
\hline
\end{tabular}

1 Different lowercase letters represent significance among different groups $(p<0.05)$. 


\section{Figure 1}

Figure $1 \mathrm{GO}$ categories in the comparison of 0 vs 5 psu (A), 0 vs 15 psu (B), and 5 vs 15 psu (C)

All genes were divided into several functional groups within three categories: cellular component, molecular function, and biological process. The below $\mathrm{x}$-axis indicated the number of genes in each category, while the above $x$-axis indicated the percentage of total genes in that category. 

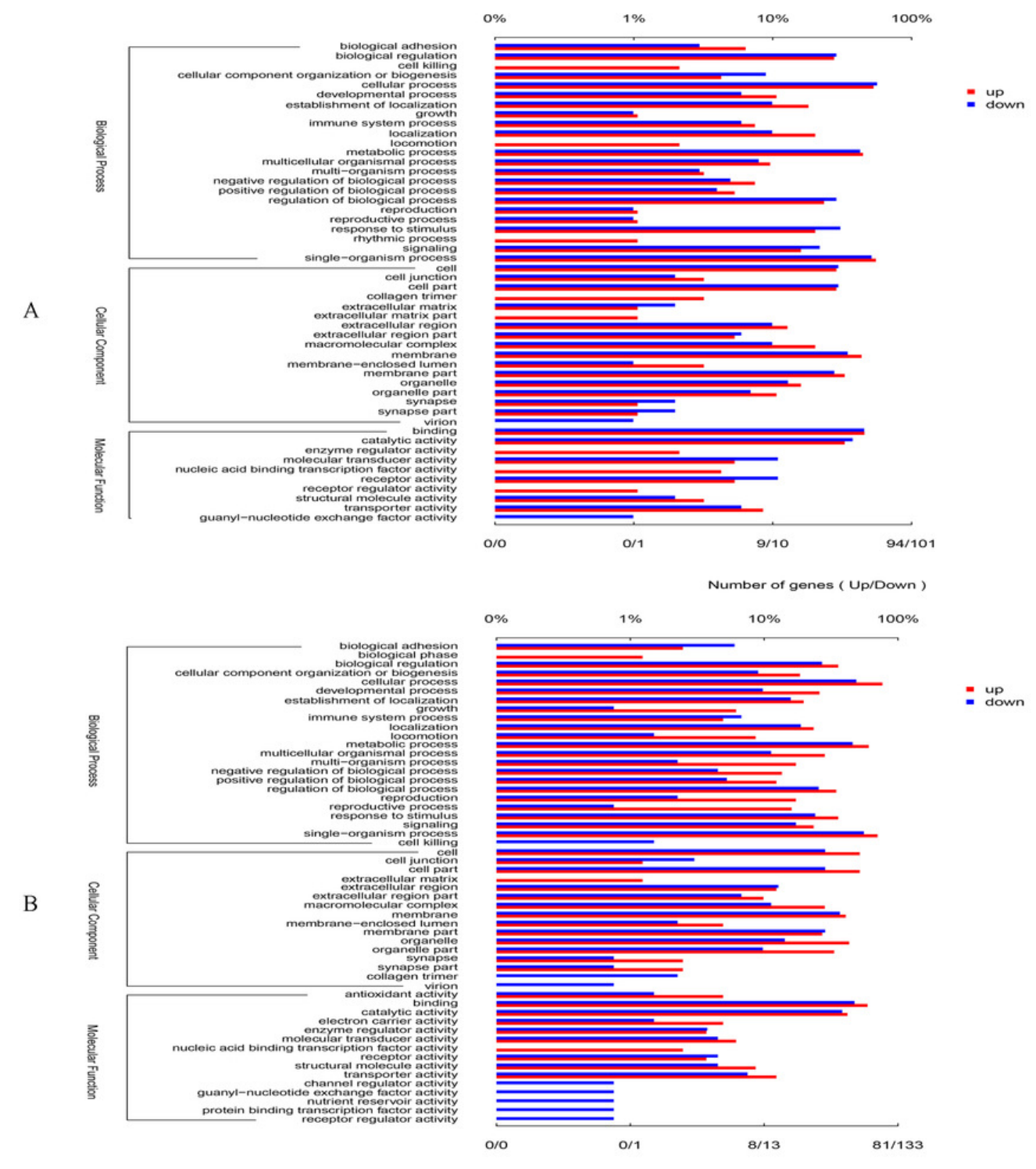

: up
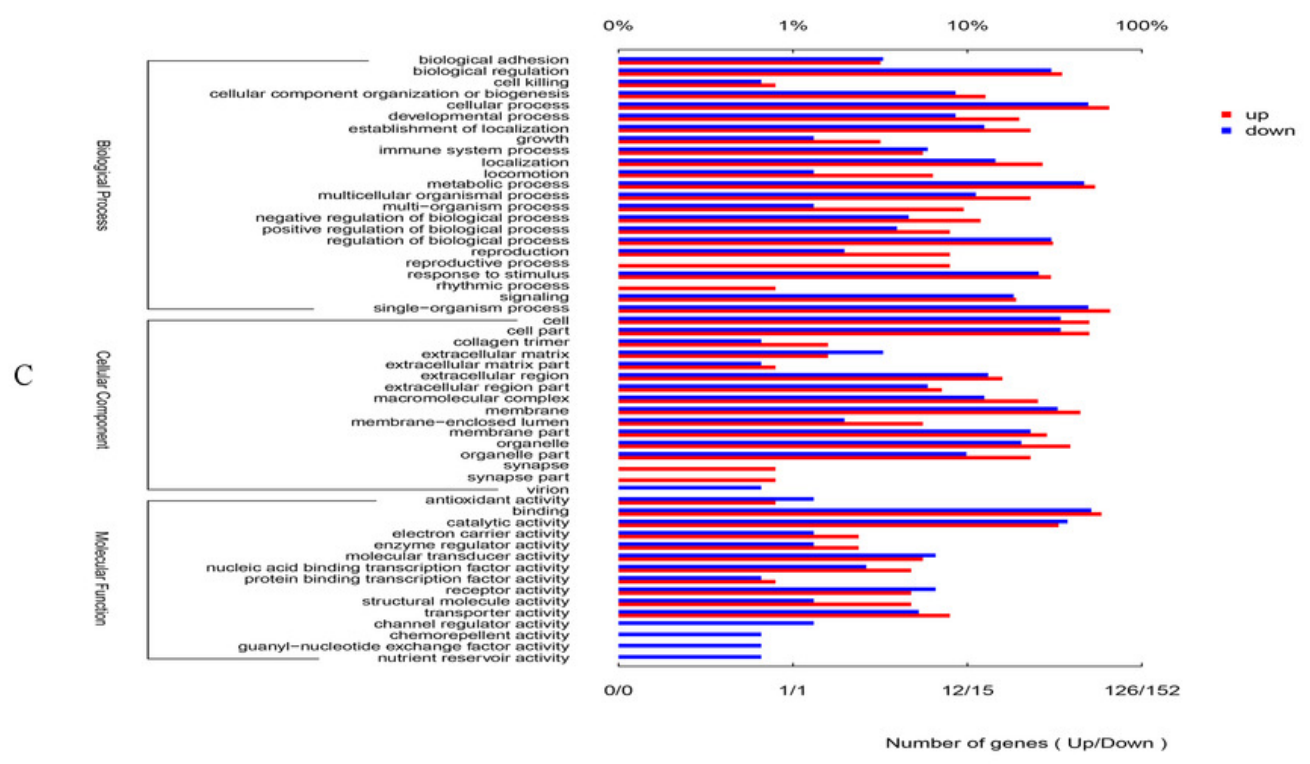


\section{Figure 2}

Fig 2. Interactions of positively selected genes and differentially expressed genes involved in the adaptation of $T$. s. elegans to high salinity

(1) NPPA plays roles in the regulation of body fluid levels and electrolytic homeostasis pathway, while $A C D C$ and $S I K$ in the pathway of lipid (glucose) metabolism by the regulation of AMPK (STK32, STK33); (2) GLUL, TAT, LAAO, SCL6A9, SLC7A9 and OAZ3, ASRGL, ASS1 play roles in the accumulation of free amino acid and urea, while KCNH5, SCN1B, SLC26A9 mainly in the process of $\mathrm{H}_{2} \mathrm{O} / \mathrm{Na}^{+}$absorption; (3) ATP6, COX1, COX3, CYTb, CYP17A1 are associated with energy production and mediated by lipid and glucose metabolism (APOE, COQ10, SAA, ADH4, FADS6, HK, MIP, GCK, LaCD, GLO and RBCS). 


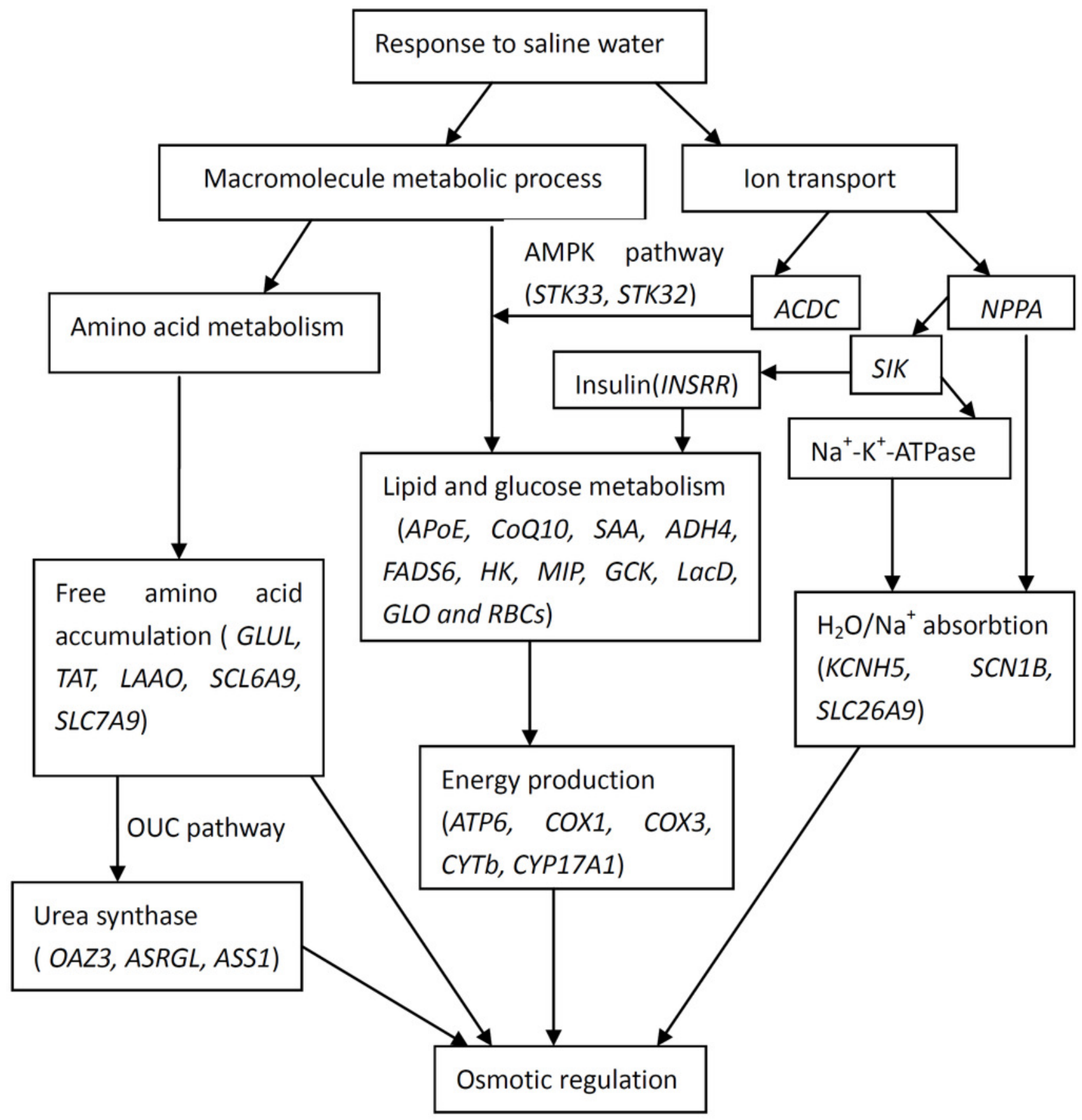

